\title{
A Response to Simulated Patient-Based Communication Skills Training for Undergraduate Medical Students at a University in Ethiopia [Letter]
}

\author{
John Asumang \\ Imperial College School of Medicine, \\ Imperial College London, London, UK
}

Correspondence: John Asumang Imperial College School of Medicine, Imperial College London, London, UK Email ja1516@ic.ac.uk

\section{Dear editor}

I read, with great interest, the article by Agago et $\mathrm{al}^{1}$ assessing interactive methods of communication skill acquisition among medical students. As a medical student, I have seen both methods utilised extensively for the betterment of communication skills (CS) throughout my time at medical school and commend the authors on their study.

The authors emphasise the utility of simulated patient (SP) based CS training for enhancing communication skills but did not address the limitations in using an SPbased Objective Structured Clinical Examination (OSCE) as their method of assessment. One key conclusion was that SP-based communication training is superior to case-based role play for communication skills acquisition. SP OSCE is a wellestablished and validated method of assessing clinical competency and CS in general. However, given that the method of assessment and the method of training in one arm of the study were both SP-based, this likely gave an inherent advantage to those participants in the SP-based communication arm, with useful prior experience. Colletti et al have demonstrated previously that prior experience even in an SP setting generates significant improvement in future experiences and assessment. ${ }^{2}$ Importantly, the use of an OSCE setting for assessment also means that these results cannot be extrapolated to indicate acquisition of CS appropriate for clinical practice. A method of assessing communication skills in a real-world setting may provide relevant evaluation, and simultaneously allow students to apply these acquired skills to actual real-world scenarios. One such possible approach may be the mini-Clinical Evaluation Exercise, an equally validated tool that can be used to assess the clinical skills of medical students and professionals in real patient interactions. ${ }^{3}$

Further, Agago et al recommend the increased use of SP based teaching and assessment but appear not to consider case-based role play as an approach that should be promoted and incorporated into medical curricula on its own merits. One such merit is the potential benefit of experiencing the role of the patient. Assuming the role of the patient in clinical scenarios enables students to learn from a different perspective, enhancing ability to show empathy and sensitivity towards real and simulated patients, as well as allowing students to identify ineffective techniques from the viewpoint of the patient. Lim et al cite improvements not only in objective 
CS performance, but also in self-perceived confidence due to dual role play. ${ }^{4}$ As such, studies have conversely identified case-based role play as the more effective approach for CS acquisition, ${ }^{5}$ and while SP-based training is effective in developing CS that are easily transferrable to clinical practice, it is important that the benefits of role play are not diminished.

In conclusion, the findings of Agago et al demonstrate the effectiveness of SP-based training in CS acquisition. While SP-based training may show more effective acquisition of communication skills in an SP-oriented assessment, it is beneficial to employ SP-based and role play based training together, given the unique learning opportunities that each can offer.

\section{Disclosure}

The author reports no conflicts of interest for this communication.

\section{References}

1. Agago TA, Asaminew T. Simulated patient-based communication skills training for undergraduate medical students at a university in Ethiopia. Adv Med Educ Pract. 2021;12:713-721.

2. Colletti L, Gruppen L, Barclay M, Stern D. Teaching students to break bad news. Am J Surg. 2001;182:20-23. doi:10.1016/S0002-9610(01) 00651-1

3. Kogan JR, Bellini LM, Shea JA. Implementation of the mini-CEX to evaluate medical students' clinical skills. Acad Med. 2002;77:11561157. doi:10.1097/00001888-200211000-00021

4. Lim ECH, Oh VMS, Seet RCS. Overcoming preconceptions and perceived barriers to medical communication using a "dual roleplay" training course. Intern Med J. 2008;38:708-713. doi:10.1111/ j.1445-5994.2007.01522.x

5. Bosse HM, Schultz JH, Nickel M, et al. The effect of using standardized patients or peer role play on ratings of undergraduate communication training: a randomized controlled trial. Patient Educ Couns. 2012;87:300-306. doi:10.1016/j.pec.2011.10.007

Dove Medical Press encourages responsible, free and frank academic debate. The content of the Advances in Medical Education and Practice 'letters to the editor' section does not necessarily represent the views of Dove Medical Press, its officers, agents, employees, related entities or the Advances in Medical Education and Practice editors. While all reasonable steps have been taken to confirm the content of each letter, Dove Medical Press accepts no liability in respect of the content of any letter, nor is it responsible for the content and accuracy of any letter to the editor.

\section{Publish your work in this journal}

Advances in Medical Education and Practice is an international, peerreviewed, open access journal that aims to present and publish research on Medical Education covering medical, dental, nursing and allied health care professional education. The journal covers undergraduate education, postgraduate training and continuing medical education including emerging trends and innovative models linking education, research, and health care services. The manuscript management system is completely online and includes a very quick and fair peer-review system. Visit http://www.dovepress.com/testimonials.php to read real quotes from published authors. 